\title{
Optimal Placement and Sizing of Distributed Generation Sources in Distribution Networks Using SPEA Algorithm
}

\author{
Ouail Mohamed ${ }^{1}$, Matallah Mohamed ${ }^{2}$, and Abdelkader Kansab ${ }^{3}$ \\ ${ }^{1}$ Faculté de Technologie - Département d'électrotechnique. Université Hassiba Benbouali Chlef -Algeria \\ ${ }^{2}$ LESI Laboratory, University Djilali Bounaama of Khemis Miliana, Khemis Miliana, Algeria \\ ${ }^{3}$ Faculté de Technologie - Département d'électrotechnique. Université Hassiba Benbouali Chlef -Algeria \\ mohamed.ouail@g.enp.edu.dz
}

Abstract: Distribution grids are being transformed from passive to active networks by integrating distributed generation (DG). In this paper, a Strength Pareto Evolutionary Algorithm (SPEA) has been used to estimate the best type of DGs and their optimal capacity and location in a 33-node radial distribution network. In order to improve the voltage stability, expressed by its index, and to reduce the active and reactive power losses, multiple scenarios have been proposed and compared. The backward/forward sweep method of distribution load flow was used to evaluate the three objective functions. The same distribution network has been also used to show the effect of the capacity and location of the DGs on the objective functions.

Keywords: distributed generation (DG), optimal distributed generation placement, Voltage Stability Index, Genetic algorithm, Strength Pareto Evolutionary Algorithms (SPEA).

\section{Introduction}

The increase in electricity demand, technological advancements in the grid integration of renewable energy sources, environmental concerns and the restructuring of electricity market have significantly motivated the network integration of DG units. Moreover, DGs are available in modular units, and are characterized by ease of finding sites for smaller generators, shorter construction times, and lower capital costs. Distributed Generation (DG) is defined as "an electric power source connected directly to the distribution network or on the customer site of the meter' [1]. DGs should be strategically placed in distribution networks for grid reinforcement, reducing power losses and on-peak operating costs, and improving voltage profiles and load factors [2],[3]. DGs also affect power quality, stability, reliability, and protection. Since DG units have a small capacity compared to central power plants, the impacts are minor if the penetration level is low $(1 \%-5 \%)$. However, if the penetration level of DG units increases to the anticipated level of $20 \%-30 \%$, the impact of DG units will be profound [4.],[5].The planning of the electric system with the presence of DGs requires defining several factors including the best technology to be used, the size, location and capacity of each unit, the interconnection method, etc. [6],[7].

Optimal location, size, type and number are the design variables which are alternatively computed for each DG. The authors in [8], [9] introduce a review about several investigations on this subject. The selection of the best places for installation and the size of the DG units in large distribution system is a complex combinatorial optimization problem [10]. The optimal installation of DGs into existing distribution networks is subjected to electrical network operating constraints, DG operation constraints and investment constraints. The distribution network must be kept within operational and design limits at all times to provide good-quality energy and avoid damage to the equipment.

Different methods have been used to keep the network within operational limits and to optimize the steady state impacts of DGs integration. These methods can be classified into three types: analytical, numerical and heuristic. Analytical methods have been used in [11], [12] to

Received: November $12^{\text {nd }}, 2017$. Accepted: June $27^{\text {th }}, 2019$

DOI: $10.15676 /$ ijeei.2019.11.2.7 
Numerical Methods such as Linear Programming used in [13] and Nonlinear Programming used in [14] have been proposed to solve the optimal DG placement. Heuristic Methods such as Genetic Algorithm (GA) and Artificial Bee Colony (ABC) are required for optimization problems that try to satisfy either one or several objectives with discrete or continuous decisions variables. The Genetic Algorithm (GA) presents the advantage to explore the space of the feasible solutions from a set of solutions created in a random manner. GA have been used to solve multi-objective Optimal DG placement problem in [15], [16], [17]. It is also used in [18] to minimize power loss cost. In [19], a non dominated sorting GA (NSGA) is used to maximize the distributed wind power integration.

The voltage stability phenomenon has been well recognized in distribution systems. Radial distribution systems having a high resistance to reactance ratio cause a high power loss so that the radial distribution system is one of the power systems which may suffer from voltage instability [20]. In certain industrial areas, it has been observed that under certain critical loading conditions, the distribution system experience voltage collapse. Voltage collapse is a local phenomenon. It occurs at a node within the area with high loads and low voltage profile [21]. It is more practical using DGs to solve the most critical problems, especially with the development of their technologies including photovoltaic, wind turbine, fuel cells, small and micro-sized turbine packages, internal combustion engine generators, and reciprocating engine generators [22].

A literature survey shows that a lot of work has been conducted on the optimization of design variables (number, type, location and size) in distributed networks in order to improve proposed objective functions (min power loss, min cost, max profit, max DG capacity, max benefit/cost ratio, voltage stability). To the knowledge of the authors, none of precedent works has combined voltage stability and active and reactive power loss that are considered as very important objective functions.

In this paper a multi-objective GA, strength pare to evolutionary algorithms (SPEA), has been used to find the optimal DG location and size considering the type and number of installed DGs in a radial distribution system. The problem is solved to improve the voltage stability, reducing active power loss and reactive power loss. A comparison between optimal design variables of two different load states has been conducted in order to demonstrate the effect of the load state on the optimization process. A comparison between integrating a single DG and a multiple DGs with the same power injection in a distributed network has also been conducted. The effect of DG capacity and location on the objective functions has been analyzed. A steady state voltage stability index is used to assess the network stability.

\section{Types of DGs}

In this study four major types of DG have been considered. DG classification is based on their terminal characteristics in terms of real and reactive power delivering capability; Different types of the DG's can be characterized as [6]:

Type 1: DG capable of injecting both real and reactive power, e.g. synchronous machines.

Type2: DG capable of injecting real but consuming reactive power, e.g. induction generators used in the wind farms.

Type3: DG capable of injecting real power only, e.g. photovoltaic panels.

Type4: DG capable of injecting reactive power only, e.g. kvar compensator, synchronous compensator, capacitors etc.

To have an idea about the effect of distributed generators capacity of each type on the system behavior, the active Penetration Level (APL) and the reactive Penetration Level (RPL)parameters are respectively defined as the ratio of the total active power and reactive power generation from DGs $\left(\sum P_{d g}, \sum Q_{d g}\right)$ to the active and reactive power peak load demand $\left(\sum P_{\text {peak }}\right),\left(\sum Q_{\text {peak }}\right)$. 
They can be calculated as:

$$
A P L=\frac{\sum p_{d g}}{\sum P_{\text {peak }}} * 100 \quad R P L=\frac{\sum Q_{d g}}{\sum Q_{\text {peak }}} * 100 \%
$$

\section{Problem formulation}

The optimization problem is formulated to improve the distribution network stability while reducing power loss by optimally selecting the location, number and size of different types of DGs using a Genetic Algorithm, Strength Pareto Evolutionary Algorithm (SPEA). The backward/ forward sweep method of distribution load flow [23] has been used to evaluate the desired objective. The constraints of the proposed problem include voltage limits at each bus, and the feeder and DG capacity limits.

\section{A. Objective Function}

\section{A.1. Voltage Stability Index}

A steady state voltage stability index is proposed by M. Charkravorty et.al in [24] and has been used in [21] and [25] for identifying the node which is most sensitive to voltage collapse. Figure 1 shows the electrical equivalent of a radial distribution system.

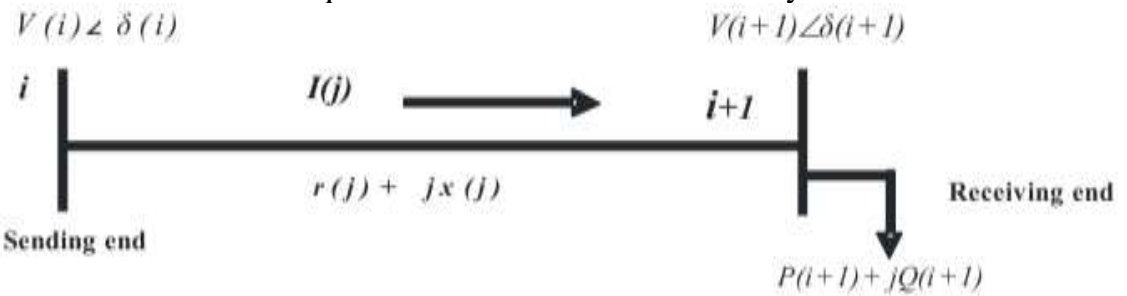

Figure 1. Electrical equivalent of two-node system [21]

$$
S I(i+1)=\left\{|V(i)|^{4}\right\}-4.0\{P(i+1) x(j)-Q(i+1) r(j)\}^{2}-4.0\{P(i+1) r(j)+Q(i+1) x(j)\}|V(i)|^{2}
$$

Where

SI $(i+1)=$ voltage stability index of node $i+1$.

$\mathrm{j}=$ branch number,

$\mathrm{i}=$ sending end node,

$\mathrm{i}+1=$ receiving end node,

$I(j)=$ current of branch $j$,

$\mathrm{V}(\mathrm{i})=$ voltage of node $\mathrm{i}$,

$\mathrm{V}(\mathrm{i}+1)=$ voltage of node $\mathrm{i}+1$,

$\mathrm{P}(\mathrm{i}+1)=$ total real power load fed through node $\mathrm{i}+1$,

$\mathrm{Q}(\mathrm{i}+1)=$ total reactive power load fed through node $\mathrm{i}+1$.

For stable operation of the radial distribution networks, SI (i+1) must be $\geq 0$.

The node at which the value of the stability index is minimum is more sensitive to the voltage collapse. The minimum SI is considered as an objective function in this investigation.

\section{A.2. Minimizing the total active and reactive power losses}

\section{Minimise}

$\left\{P_{L}=\sum_{k=1}^{n}\left|I_{k}\right|^{2} R_{k}\right\}$

Minimise

$\left\{Q_{L}=\sum_{k=1}^{n}\left|I_{k}\right|^{2} X_{k}\right\}$

Where:

n=nbus- 1

\section{B. Constraints}

\section{B.1. Voltage limits on each bus}

Make sure that the voltages $\left|v_{i}\right|$ along the feeder are well within the tolerable range, $\pm 5 \%$ of the nominal value[26]. 


$$
0.95 \leq\left|v_{i}\right| \leq 1.05 \quad i=1,2, \ldots \ldots \text { nbus }
$$

B.2. Feeder capacity limits:

$$
0 \leq I_{i j} \leq I_{i j \max } \quad \forall i, j
$$

B.3. DG Power Limits:

$$
p_{D G, i}^{P} \leq P_{D G, i}^{M A X}, Q_{D G, i}^{P} \leq Q_{D G, i}^{M A X}
$$

Where $P_{D G, i}^{M A X}$ and $Q_{D G, i}^{M A X}$ are the allowable maximum active and reactive powers for the $i t h \mathrm{DG}$ unit.

\section{Strengthpare to evolutionary algorithms}

This approach has been proposed par Ziztler[27]; itis implemented with the help of genetic algorithm and is based on the maintenance of elitism in the population by the constitution of an external set of non-dominated solutions. The elitism techniques try to keep the non-dominated solutions along the procedure of research of the solutions.

To every generation, the set is actualized according to the new non-dominated solutions. The algorithm starts with a population of size $\mathrm{N}$ generated in an uncertain manner with anempty external set. To every t generation, the setis filled and actualized by the non-dominated solutions gotten from the current population.

The notion of dominance permits us to identify the optimal Pareto solutions forming the border of Pareto. For a problem of minimization, a solution xi dominates a solution $\mathrm{xj}$ if and only if:

$$
\forall m \in[1, n], \quad f_{m}\left(x_{i}\right) \leq f_{m}\left(x_{j}\right) \text { et } \exists m \in[1, n], f_{m}\left(x_{i}\right)<f_{m}\left(x_{j}\right)
$$

$f_{m}$ is an objective function.

\section{The Algorithm of SPEA [28]:}

Step 1: initialization: an initial population $P_{t}$ will be created as well as an empty external set $\bar{p}_{t}$. ( $t=0 ; \mathrm{N}=$ Population size). The initial population is randomly generated (The set of candidate buses and DGs size are limited).

Step 2: updating of the external set: All individuals of $P_{t}$ whose decision vectors are no dominated will be copied into a current version of the external set $\overline{\mathrm{P}}^{\prime}$. Individuals that become weakly dominated will be removed. Finally, the new external set can be defined as $\bar{P}_{t+1}=\overline{\mathrm{P}}^{\prime}$

Step 3: fitness assignment: to all the individuals of the external set $i \in \bar{P}_{t}$, the strength value will be assigned firstly: $(i) \in[0,1]$. The strength is measured by the number of dominated solutions, divided by the population size $\mathrm{N}+1$, and thus proportional to the population size $\left(n_{i}\right.$ number of solutions dominated by $i$ ):

$$
S_{i}=\frac{n_{i}}{N+1}
$$

Once the strength values $(i)$ are defined, the fitness values can be calculated. For the external set the fitness value of ïs equal to the strength value: $(i)=(i)$. For $j \in P_{t}$ the fitness is the sum of all strength values of the dominated items in the external set, plus one, to ensure that the external set is having a lower value than the population:

(j) $=1+\sum_{\mathrm{i} \in \bar{P}_{t}}(\mathrm{i})(i$ dominate $\mathrm{j})$

Step 4: selection: for this, two random individuals of both sets are chosen $(i, j) \in \overline{P_{t}}+P_{t}$ and compared. The one with the lower fitness value will be included in the next generation.

Step 5\& 6: recombination and mutation: the individuals inside the population will be modified depending on recombination and mutation probability parameters. The recombination recombines two individuals into new solutions, while the mutation is flipping genesrandomly. 
Step 7: constraints check: the new individuals will be checked against the constraints. In this work, it have been proposed to replace those genes randomly by others surviving the constraint.

Step 8: termination criterion: if stopping criteria are satisfied (fixed number of iteration), the algorithm will stop here: The best solutions are stored in the external set. Otherwise, the algorithm continues on to Step 2 with the next generation.

\section{Results and analysis}

The simulations have been carried out in MATLAB environment.

A. Effect of active and reactive power injection on objective functions

The Effect of active and reactive power injection on objective functions are evaluated in the test 33-bus radial distribution network; a constant power load model has been used in the simulation. The detailed data for this system is given in table 1 in the Appendix [29].Figure 2 illustrates the network structure of the system.

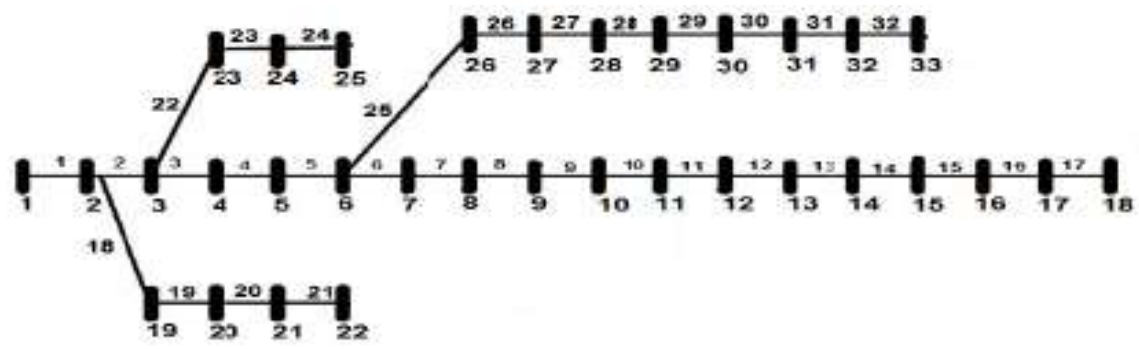

Figure 2. 33-bus test distribution system [29]

A mesh plot have been used to evaluate the stability index, the total active power losses and the total reactive power losses in the 33-bus distributed network versus the location and size of both active and reactive power injection. Figure. 3 shows that the active power injection affect the stability index more than the reactive power injection and the improvement level increase as the penetration level increase. However, the constraints -see section III.B- limit the penetration level of DGs. The location and the size have the principal effect on the objective functions. Figure. 4 and Figure. 5 show the total active and reactive power losses of the system for different locations and sizes of the DG units.

It can be observed that the highest reduction in power losses does not take the same location and size where the highest improvement in system stability. If the system face a critical problem of stability, it is better to consider only one objective function to prevent the voltage collapse. If the interests are to enhance different parameters such as stability and power losses, the SPEA can find the optimal solution.
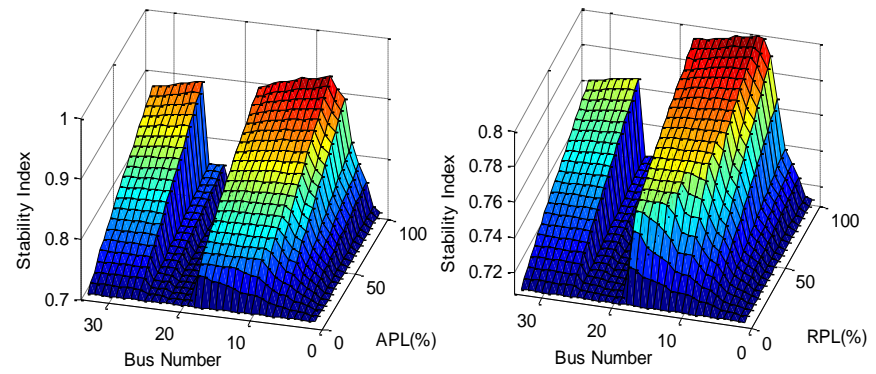

Figure 3. Effect of capacity and location of DG on Stability Index 

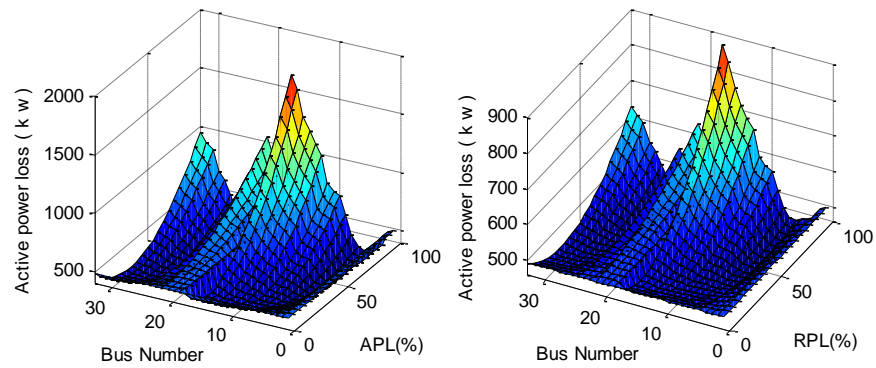

Figure 4. Effect of capacity and location of DG on active power losses
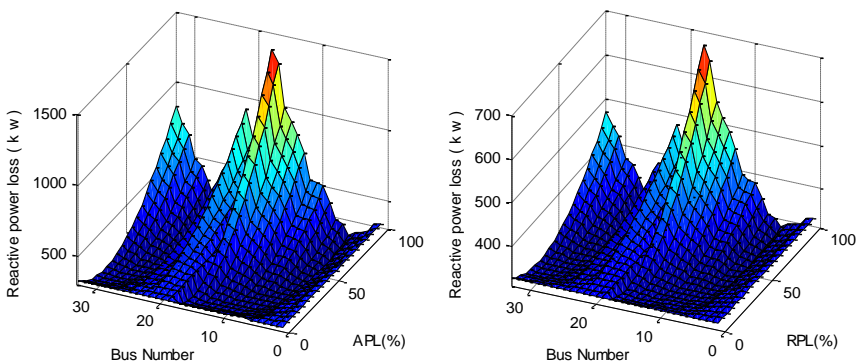

Figure 5. Effect of capacity and location of DG on Reactive power losses

\section{A. SPEA investigation progress for two objective functions}

The SPEA investigation progress for two objective functions has been tested for 12-bus radial distribution network; a summary of system data is presented in Table 2 in the Appendix[30]. Figure 6 illustrates the network structure of the system.

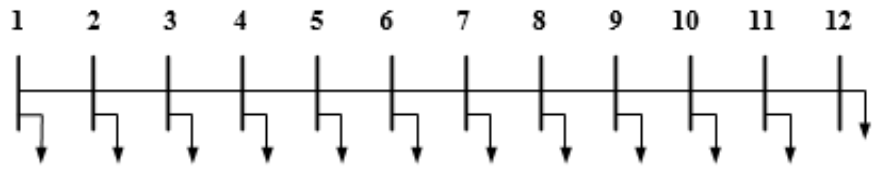

Figure 6. 12-bus and 11 branches system

Figure 7 represents SPEA progress on the 12 Bus system, to select optimal location and size of one DG type 1 to minimize the total active power loss and maximize the stability index.

In order to show clearly the progress of population selection, a minimization problem has been taken. In this test, two objective functions have been used, the total active power loss and the parameter $\frac{1}{1+\mathrm{SI}}$ instead of the SI (the stability index). It is observed fromFigureure-7- that the no dominated solution has been selected among the total population. It is also noted that the search for the solution does not sweep all the area because of the constraints that have been taken in consideration.

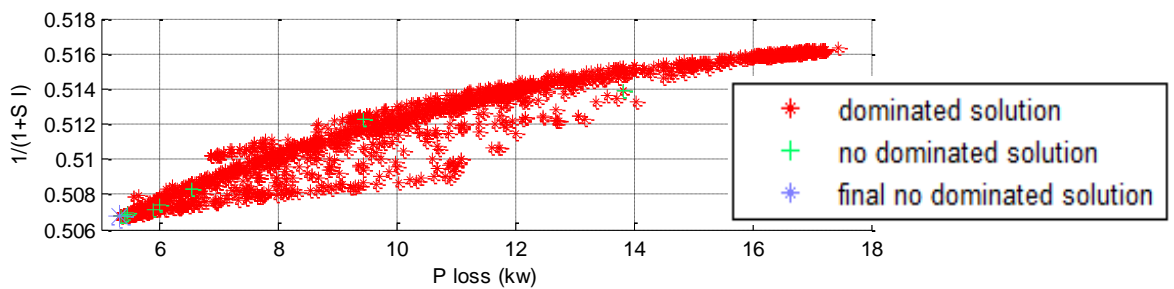

Figure 7. SPEA progress in selecting optimal location and size of DG type 1 
B. Selecting optimal location and size of different types of DGs using SPEA algorithm

The parameters of the genetic algorithm, SPEA, selected for optimization are: Population size $(\mathrm{N}=10)$, recombination probability $(\mathrm{Pr}=0.8)$ and mutation probability $(\mathrm{Pm}=0.03)$. The GA is set to stop when 150 iterations are evaluated.

In this study, after validation of the program, three cases have been analyzed depending on the number and type of DGs to be installed. The first case considers only one connected DG type. The second case, four different connected DG sare considered to be installed optimally. For the two cases, the algorithm is applied on a modified 33-bus distribution system. This system works at the nominal voltage of $12.66 \mathrm{kV}$ and the base apparent power is $10 \mathrm{MVA}$. In addition, the maximum currents limit of the system branches is selected to be $255 \mathrm{~A}[31]$.

The third case considers two connected DGs to a 119-bus network. This system functions at 11 $\mathrm{kV}$ nominal voltage. The detailed data for this system is given in table 3 in the Appendix [29].

\section{Validation of the program:}

In order to validate the implementation of the SPEA algorithm in our MATLAB program, a comparison with the results presented on Figure 3 where only the voltage stability index is considered as objective function. The case of one DG of type 3 , active power injection, and type 4 , reactive power injection, is used for validation purposes.

The SPEA algorithm is meant to find the optimal placement and size for this case. From table 1, it can be noted that the optimal location and size presented by the algorithm are the parameters presenting the highest voltage stability index among all other locations and sizes.

Table 1. Optimal location and sizes of DG using SPEA algorithm.

\begin{tabular}{|c|c|cc|c|}
\hline \multirow{2}{*}{ DG } & Optimal location & \multicolumn{2}{|c|}{ Optimal size } & Stability Index \\
\hline type 3 & 8 & 99.89 & 0 & 0.92 \\
\hline type 4 & 9 & 0 & 99.50 & 0.79 \\
\hline
\end{tabular}

Case-I: One DG is connected Considering two load states of the 33-bus distribution system, SPEA algorithm was used to find the optimal location and size for type 1, type 3 and type 4 independently. The maximum penetration of DG in the network is limited: APL max $=30 \%$, RPL $\max =30 \%$. The optimal size and locations obtained for each type in the first and second load state are given in Table 2 and Table 3.

\section{The objective functions without $D G$ integration:}

First load state: Stability index=0.71, Active power loss $=493.07 \mathrm{~kW}$, Reactive power loss $=328$. 178kvar. Second load state: Stability index $=0.68$, Active power loss $=579.18 \mathrm{~kW}$, Reactive power loss=391.42 kvar.

Table 2. Optimal location and sizes of DG in the first load state.

\begin{tabular}{|c|cccc|c|cc|}
\hline \multirow{2}{*}{ DG type } & $\begin{array}{c}\text { Optimal } \\
\text { location }\end{array}$ & \multicolumn{2}{c|}{$\begin{array}{c}\text { Optimal size } \\
\text { (APL\%) }\end{array}$} & (RPL\%) & Stability Index & \multicolumn{2}{c|}{ Power loss } \\
\hline type 1 & 10 & 27.44 & 29.49 & 0.81 & 227.09 & $(\mathrm{KVAR})$ \\
\hline type 3 & 11 & 29.90 & 0 & 0.80 & 268.95 & 178.94 \\
\hline type 4 & 13 & 0 & 29.94 & 0.76 & 440.65 & 293.42 \\
\hline
\end{tabular}

Table 2 and 3 show that the SPEA algorithm can find the optimal location and size of each DG type integration, and The network stability and energy losses depend on the network load state. It can be noted that the stability index is improved and the system power losses are reduced in each load state after the integration of DG especially for type 1. It can be observed that when a DG unit of type 1is considered, the stability index is improved over $10 \%$, and the active and 
reactive power losses are reduced over $55 \%$ in the two load states. The optimal placement and size at the first state is not the same as the second. Therefore, to benefit more from DGs integration, the optimal location and size should be investigated according to different load variations data during one year.

Table 3. Optimal location and sizes of DG in the second load state.

\begin{tabular}{|c|c|c|c|c|c|c|}
\hline \multirow{2}{*}{ DG type } & Optimal & Optimal & size & \multirow{2}{*}{ Stability Index } & \multicolumn{2}{|c|}{ Power loss } \\
\hline & location & (APL\%) & (RPL\%) & & $(\mathrm{KW})$ & (KVAR) \\
\hline type 1 & 30 & 29.77 & 28.54 & 0.79 & 203.90 & 139.58 \\
\hline type 3 & 31 & 29.439 & 0 & 0.77 & 259.01 & 174.37 \\
\hline type 4 & 31 & 0 & 29.41 & 0.73 & 507.96 & 343.35 \\
\hline
\end{tabular}

Figure 8 show the impact of DG on voltage profile considering only one type optimally installed. It can be observed that the greatest improvement on voltage profile is achieved when the DG units of type 1 is integrated.

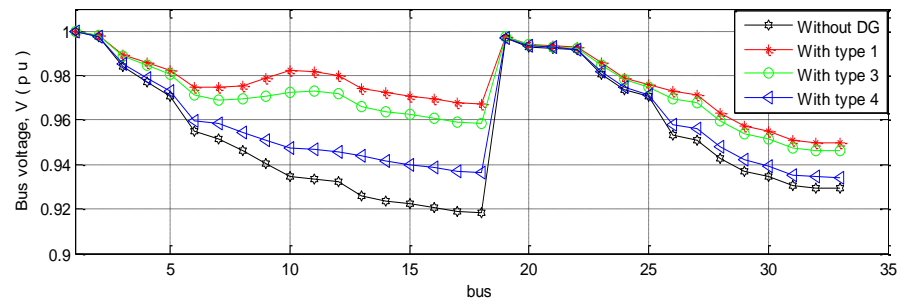

Figure 8. Voltage profile before and after integrating of DGS in the first load state

Case-II: four DGsare connected: in order to compare with the first case, the total active and reactive penetration of DGsare limited to $30 \%$. (The first load state has been used in the investigation).

In this case, three scenarios have been investigated to show the effect of DGs number on the voltage stability and the power losses.

Scenario1: four DG units of type 3 have been installed. Maximum penetration of each unit is APLmax $=(30 / 4) \%$, RPLmax $=(30 / 4) \%$. The optimal sizes and locations obtained are given in Table 4.

Scenario2: four DG units of type 4 have been installed. Maximum penetration of each unit is APLmax $=(30 / 4) \%$, RPLmax $=(30 / 4) \%$. The optimal sizes and locations obtained are given in Table 5.

Scenario3: two DG units of type 3 with two DG units of type 4 have been installed. Maximum penetration of each unit is APLmax $=(30 / 2) \%$, RPLmax $=(30 / 2) \%$. The optimal sizes and locations obtained are given in Table 6 .

Table 4. Optimal locations and sizes of the four DG units of type 3.

\begin{tabular}{|c|c|c|c|c|c|c|c|}
\hline \multicolumn{4}{|c|}{ Optimal location } & \multicolumn{4}{|c|}{ Optimal size } \\
\hline DG unit 1 & DG unit 2 & DG unit 3 & DG unit 4 & $\begin{array}{l}\text { DG unit } 1 \\
\text { (APL\%) }\end{array}$ & $\begin{array}{l}\text { DG unit } 2 \\
\text { (APL\%) }\end{array}$ & $\begin{array}{c}\text { DG unit } 3 \\
\text { (APL\%) }\end{array}$ & $\begin{array}{c}\text { DG unit } 4 \\
\text { (APL\%) }\end{array}$ \\
\hline 31 & 29 & 18 & 13 & 7.50 & 7.49 & 7.46 & 7.50 \\
\hline \multirow{2}{*}{\multicolumn{4}{|c|}{ Stability Index }} & & \multicolumn{2}{|c|}{ Power loss } & \\
\hline & & & & & $(\mathrm{KW})$ & (KVAR) & \\
\hline \multicolumn{4}{|c|}{0.84} & & 212.11 & 138.62 & \\
\hline
\end{tabular}


Table 5. Optimal locations and sizes of the four DG units of type 4.

\begin{tabular}{|c|c|c|c|c|c|c|c|}
\hline \multicolumn{3}{|c|}{ Optimal location } & \multicolumn{4}{c|}{ Optimal size } \\
\hline $\begin{array}{c}\text { DG } \\
\text { unit 1 }\end{array}$ & DG unit 2 & DG unit 3 & DG unit 4 & $\begin{array}{c}\text { DG unit 1 } \\
\text { (RPL\%) }\end{array}$ & $\begin{array}{c}\text { DG unit 2 } \\
(\text { RPL\%) }\end{array}$ & $\begin{array}{c}\text { DG unit 3 } \\
\text { (RPL\%) }\end{array}$ & $\begin{array}{c}\text { DG unit 4 } \\
\text { (RPL\%) }\end{array}$ \\
\hline 29 & 13 & 18 & 31 & 7.50 & 7.50 & 7.50 & 7.50 \\
\hline \multicolumn{3}{|c|}{ Stability Index } & \multicolumn{3}{c|}{ Power loss } \\
\hline \multicolumn{3}{|c|}{0.795} & & 410.24 & 273.33 \\
\hline
\end{tabular}

Table 6. Optimal locations and sizes of the four DG units of type 3 and 4.

\begin{tabular}{|c|c|c|c|c|c|c|c|}
\hline \multicolumn{4}{|c|}{ Optimal location } & \multicolumn{4}{|c|}{ Optimal size } \\
\hline $\begin{array}{l}\text { DG unit } 1 \\
\text { (Type 3) }\end{array}$ & $\begin{array}{c}\text { DG unit } 2 \\
\text { (Type 3) }\end{array}$ & $\begin{array}{l}\text { DG unit } \\
\text { (Type 4) }\end{array}$ & $\begin{array}{c}\text { DG unit } 4 \\
\text { (Type 4) }\end{array}$ & $\begin{array}{l}\text { DG unit } 1 \\
\text { (APL\%) }\end{array}$ & $\begin{array}{c}\text { DG unit } 2 \\
\text { (APL\%) }\end{array}$ & $\begin{array}{c}\text { DG unit } 3 \\
\text { (RPL\%) }\end{array}$ & $\begin{array}{c}\text { DG unit } 4 \\
\text { (RPL\%) }\end{array}$ \\
\hline 15 & 31 & 30 & 18 & 14.22 & 13.83 & 12.88 & 13.15 \\
\hline \multicolumn{4}{|c|}{ Stability Index } & \multicolumn{4}{|c|}{$\frac{\text { Power loss }}{\text { (KVAR }}$} \\
\hline \multicolumn{4}{|c|}{0.87} & & 164.34 & 106.29 & \\
\hline
\end{tabular}

The optimal location and size of each DG unit for different scenarios are shown in table 4 to 6. Comparing with the first case, table 4 and 5 show that the number of DGs affects significantly the stability and the power losses. It is observed from there sults that four optimally installed DGs present better voltage stability and less power losses than one installed DG with the same total size. It is also observed from the results in table 6 that when DGs of different types are installed optimally, a higher loss reduction and stability improvement can be achieved.

A comparison between the voltage stability index obtained by integration of one DG type 1 and the one obtained in the scenario 3 is illustrated in Figure 9.

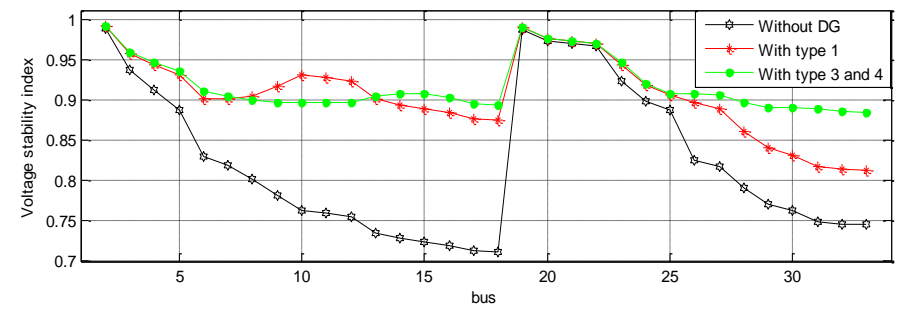

Figure 9. Voltage stability index before and after integrating of DGS

It is noted from the results given in case-I and case-II that an optimal integration of several small DGs with deferent types improves the stability of the network and reduce the energy loss more than the use of one DG of important size. Moreover, the reliability of the power injection is increased.

Case III: Two different DGs are connected to the modified IEEE 119-node test feeder (Figure 10) [29]. The first one is a type 3 DG with a maximum capacity of 1,9 MW and the second one is considered as a set of reactive compensators (type $4 \mathrm{DG}$ ) of $0.2 \mathrm{MVA}$. This test system is an $11 \mathrm{kV}$ distribution system. 


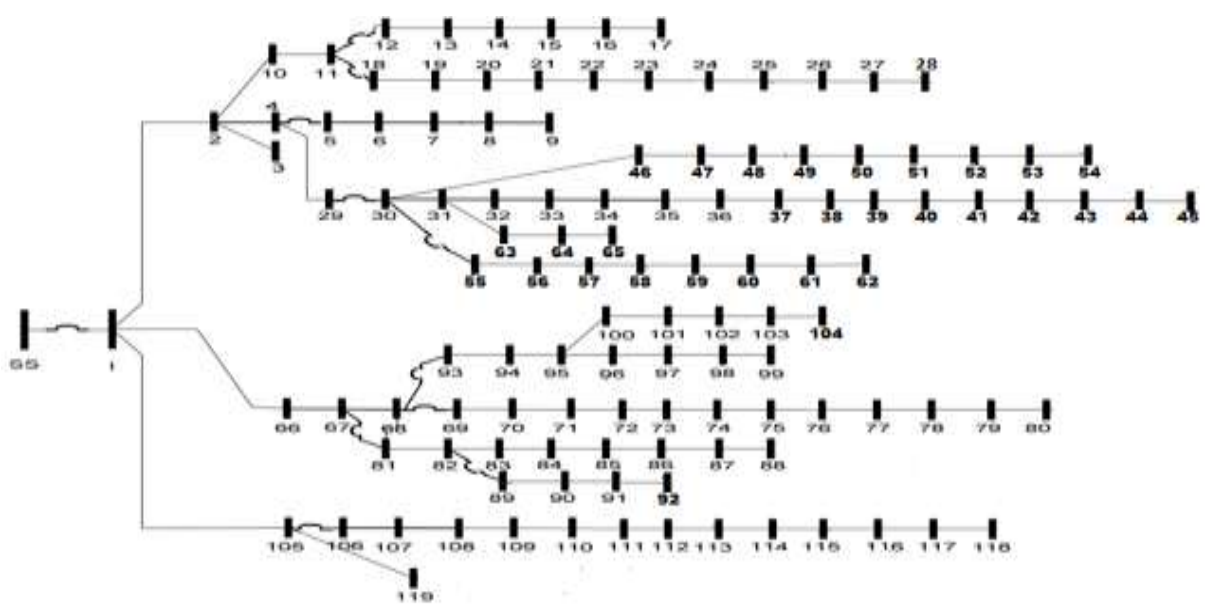

Figure 10. The modified 119-bus test system[29]

Table 7. Optimal locations and size of the two DG units of type 3 and 4.

\begin{tabular}{|c|c|c|c|}
\hline \multicolumn{2}{|c|}{ Optimal location } & \multicolumn{2}{c|}{ Optimal size } \\
\hline DG type 3 & DG type 4 & DG type 3 (APL\%) & DG type4(RPL\%) \\
\hline 79 & 80 & 9.985 & 35.794 \\
\hline \multicolumn{2}{|c|}{ Stability Index } & \multicolumn{2}{c|}{ Power loss } \\
\hline \multicolumn{2}{|c|}{0.7954} & \multicolumn{2}{c|}{1577.7} \\
\hline
\end{tabular}

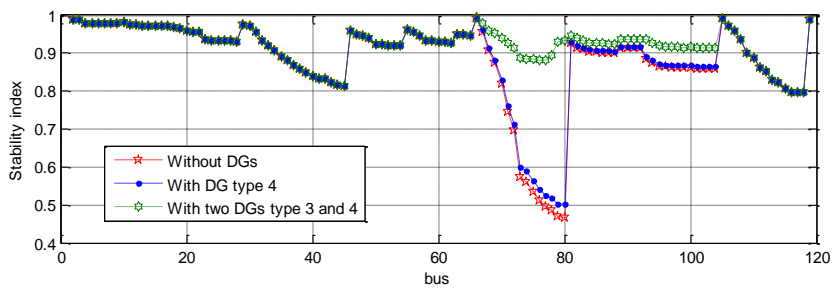

Figure 11. Voltage stability index before and after integrating DGs

The optimal locations and size of the two DGs are presented in table 7. Results show that the optimal placement is situated at a node within the area with high loads and that the optimal size of DGs is their full capacity. The voltage stability index of all buses before and after integrating DGs is presented in Figure 11 it can be noticed that only the feeder of buses 66 to 104 had it stability index effected by the integration of DGs. This can be explained by the fact that the DGs are present only on this feeder branch and that the different feeders are separated. Under these circumstances, the effects of the DGs are limited to this feeder branch.

It can also be noticed that the integration of the type 4 DG didn't improve much the stability index of the affected set of buses while a great improvement of the index occurred with integration of a type 3 DG. It is worth mention that our algorithm operates normally with large systems.

\section{Conclusion}

In this paper, SPEA algorithm has been used to investigate the optimal DG placement and size in a distributed network. The optimization problem has been formulated in order to improve voltage stability and minimize total active and reactive power losses for integration of different DG types. Penetration level of DG, voltage and current limit are considered as the constraints in 
the optimization process. A steady state voltage stability index has been used to assess the stability at each node. A 33-node distribution network has been used for the simulation. Illustrative mesh plots were given in this paper to show the impacts of DGs locations and sizes on the voltage stability and power losses. The proposed algorithm has been used in different scenarios to show the effect of the type and the number of DGs integration on the distributed network. The location, size and type of DGs significantly affect the voltage stability and the power losses. The algorithm proposed in this paper can find a compromise between different objective functions providing useful information for optimal DGs integration.

\section{References}

[1]. Jenkins N, Allan R, Crossley P, Kirschen D, Strbac G. Embedded generation. London: Institution of Electrical Engineers; 2000.

[2]. IEEE Standard for Interconnecting Distributed Resources with Electric Power Systems, IEEE Standard 1547-2003(R2008), 2003.

[3]. ZHAN et al, "relay protection coordination integrated optimal placement and sizing of dg sources," IEEE Transactions on smart grid, March 30. 2015.

[4]. Y. M. Atwa and E. F. El-Saadany, "Optimal allocation of ESS in distribution systems with a high penetration of wind energy," IEEE Trans. Power Syst., vol. 25, no. 4, pp. 18151822, Nov. 2010.

[5]. AL ABRI et al, "Optimal placement and sizing method to improve the voltage stability margin," IEEE Transactions on power systems, vol. 28, no. 1, pp. 326-334, February 2013.

[6]. J. A. Sa'ed, M. K. Jubran, S. Favuzza, F. Massaro, "Reassessment of voltage stability for distribution networks in presence of DG", Environment and electrical engineering international conference (EEEIC), IEEE, Florence, Italy,2016.

[7]. J. A. Sa'ed, S. Favuzza, M. G. Ippolito, F. Massaro, "Verifying the Effect of Distributed Generators on Voltage Profile, Power Losses and Protection System in Radial Distribution Networks", in IEEE/POWERENG, Istanbul-Turkey, pp. 1044 - 1049, May 2013.

[8]. Pavlos S. Georgilakis, Nikos D. Hatziargyriou, "Optimal distributed generation placement in power distribution networks: models, methods, and future research," IEEE Transactions on power systems, vol. 28, no. 3, pp. 3420 - 2428, AUGUST 2013

[9]. KEANE et al., "State-of-the-Art Techniques and Challenges Ahead for Distributed Generation Planning and Optimization," IEEE Transactions on power systems, August 14, 2012.

[10]. C.L.T. Borges, and D.M. Falcao, "Impact of distributed generation allocation and sizing on reliability, losses and voltage profile," IEEE Bologna Power Technology Conference, Italy, 2003.

[11]. T. Gözel and M. H. Hocaoglu, "An analytical method for the sizing and siting of distributed generators in radial systems," Elect. Power Syst. Res., vol. 79, no. 6, pp. 912-918, Jun. 2009.

[12]. D. Q. Hung, N. Mithulananthan, and R. C. Bansal, "Analytical expressions for DG allocation in primary distribution networks," IEEE Trans. Energy Convers., vol. 25, no. 3, pp. 814-820, Sep. 2010.

[13]. A. Keane and M. O'Malley, "Optimal utilization of distribution networks for energy harvesting," IEEE Trans. Power Syst., vol.22, no.1, pp. 467-475, Feb. 2007.

[14]. Y. M. Atwa and E. F. El-Saadany, "Probabilistic approach for optimal allocation of windbased distributed generation in distribution systems," IET Renew. Power Gener., vol.5, no.1, pp.79-88, Jan.2011.

[15]. G. Celli, E. Ghiani, S. Mocci, and F. Pilo, "A multiobjective evolutionary algorithm for the sizing and siting of distributed generation," IEEE Trans. Power Syst., vol. 20, no. 2, pp. 750-757, May 2005.

[16]. G. Caprinelli, G. Celli, S. Mocci, F. Pilo, and A. Russo, "Optimisation of embedded generation sizing and siting by using a double trade-off method," Proc. Inst. Electr. Eng.Gener., Transm., Distrib., vol. 152, no. 4, pp. 503-513, Jul. 2005. 
[17]. R. K. Singh and S. K. Goswami, "Multi-objective optimization of distributed generation planning using impact indices and trade-off technique," Elect. Power Compon. Syst., vol. 39, no. 11, pp. 1175-1190, Aug. 2011.

[18]. K.-H. Kim, Y.-J. Lee, S.-B. Rhee, S.-K. Lee, and S.-K. You, "Dispersed generator placement using fuzzy-GA in distribution systems," in Proc. IEEE Power Eng. Soc. Summer Meeting, Jul. 2002, pp. 1148-1153.

[19]. L. F. Ochoa, A. Padilha-Feltrin, and G. P. Harrison, "Time-series-based maximization of distributed wind power generation integration," IEEE Trans. Energy Convers., vol. 23, no. 3, pp. 968-974, Sep. 2008.

[20]. M. Moghavvemi and M. O. Faruque, "Technique for assessment of voltage stability in illconditioned radial distribution network", IEEE Power Engineering Review, pp. 58-60, January 2001.

[21]. G.V.K Murthy, et al, "Voltage Stability Analysis of Radial Distribution Networks with Distributed Generation," International Journal on Electrical Engineering and Informatics - Volume 6, Number 1, pp. 195-204, March 2014

[22]. A. Moeini et al. "Optimal dg allocation in distribution network using Strength pareto multiobjective optimization approach", International Journal on "Technical and Physical Problems of Engineering” (IJTPE), Iss. 2, Vol. 2, No. 1, Mar. 2010

[23]. William H. Kersting, Distribution system modeling and analysis, New Mexico, CRC Press, 2002.

[24]. M. Charkravorty and D. Das, "Voltage stability analysis of radial distribution networks", International Journal of Electrical Power \& Energy Systems, Vol. 23, No. 2, pp.129135,2001 .

[25]. Mohammad Hasan Hemmatpour, Mohsen Mohammadian, Ali-Akbar Gharaveisi, "Simple and efficient method for steady-state voltage stability analysis of islanded microgrids with considering wind turbine generation and frequency deviation", IET Gener. Transm. Distrib., pp. 1-12, 2016.

[26]. Amaresh Gantayet, Sudipta Mohanty, "An Analytical Approach for Optimal Placement and Sizing of Distributed Generation based on a Combined Voltage Stability Index", IEEE Power, Communication and Information Technology Conference (PCITC) Siksha 'O' Anusandhan University, Bhubaneswar, India,2015.

[27]. E. Zitzler, "Evolutionary Algorithms for Multiobjective Optimization: Methods and Applications," Ithaca: Shaker, 1999.

[28]. Philippe Schädler, Juan David Berdugo, Thomas Hanne, "A Distance-Based Pareto Evolutionary Algorithm Based on SPEA for Combinatorial Problems," 4th International Symposium on Computational and Business Intelligence, pp. 112-117, 2016.

[29]. SasanGhasemi and Jamal Moshtagh, "Radial distribution systems reconFigureuration considering power losses cost and damage cost due to power supply interruption of consumers," International Journal on Electrical Engineering and Informatics - Volume 5, Number 3, pp. 297-315, September 2013.

[30]. Kyu-Ho Kim et al, "Dispersed Generator Placement using Fuzzy-GA in Distribution Systems," IEEE, pp. 1148-1153, 2002. 


\section{Appendix}

\begin{tabular}{|c|c|c|c|c|c|c|c|c|c|c|c|c|c|}
\hline \multirow{2}{*}{$\begin{array}{c}\text { Line } \\
\#\end{array}$} & \multirow{2}{*}{$\begin{array}{l}\text { Node } \\
\quad i\end{array}$} & \multirow{2}{*}{$\begin{array}{c}\text { Node } \\
j\end{array}$} & \multirow{2}{*}{$\begin{array}{c}\mathrm{R} \\
(\Omega)\end{array}$} & \multirow{2}{*}{$\begin{array}{c}\mathrm{X} \\
(\Omega)\end{array}$} & \multicolumn{2}{|c|}{ Load at node $j$} & \multirow{2}{*}{$\begin{array}{c}\text { Line } \\
\#\end{array}$} & \multirow{2}{*}{$\begin{array}{c}\text { Node } \\
\quad i\end{array}$} & \multirow{2}{*}{$\begin{array}{c}\text { Node } \\
\quad j\end{array}$} & \multirow{2}{*}{$\begin{array}{l}\mathrm{R} \\
(\Omega)\end{array}$} & \multirow{2}{*}{$\begin{array}{c}\mathrm{X} \\
(\Omega)\end{array}$} & \multicolumn{2}{|c|}{ Load at node $i$} \\
\hline & & & & & $\begin{array}{c}\mathrm{P} \\
(\mathrm{kw})\end{array}$ & $\begin{array}{c}\mathrm{Q} \\
\text { (kvar) }\end{array}$ & & & & & & $\begin{array}{c}\mathrm{P} \\
(\mathrm{kw})\end{array}$ & $\begin{array}{c}\mathrm{Q} \\
(\mathrm{kw}) \\
\end{array}$ \\
\hline 1 & 1 & 2 & 0.0922 & 0.047 & 100 & 60 & 20 & 20 & 21 & 0.4095 & 0.4784 & 90 & 40 \\
\hline 2 & 2 & 3 & 0.493 & 0.2512 & 90 & 40 & 21 & 21 & 22 & 0.7089 & 0.9373 & 90 & 40 \\
\hline 3 & 3 & 4 & 0.3661 & 0.1864 & 120 & 80 & 22 & 3 & 23 & 0.4512 & 0.3084 & 90 & 50 \\
\hline 4 & 4 & 5 & 0.3811 & 0.1941 & 60 & 30 & 23 & 24 & 25 & 0.8980 & 0.7091 & 420 & 200 \\
\hline 5 & 5 & 6 & 0.8190 & 0.7070 & 60 & 20 & 24 & 24 & 25 & 0.8980 & 0.7071 & 420 & 200 \\
\hline 6 & 6 & 7 & 0.1872 & 0.6188 & 200 & 100 & 25 & 6 & 26 & 0.2031 & 0.1034 & 60 & 25 \\
\hline 7 & 7 & 8 & 0.7115 & 0.2351 & 200 & 100 & 26 & 26 & 27 & 0.2842 & 0.1474 & 60 & 25 \\
\hline 8 & 8 & 9 & 1.0299 & 0.7400 & 60 & 20 & 27 & 27 & 28 & 1.0589 & 0.9338 & 60 & 20 \\
\hline 9 & 9 & 10 & 1.044 & 0.7400 & 60 & 20 & 28 & 28 & 29 & 0.8043 & 0.7006 & 120 & 70 \\
\hline 10 & 10 & 11 & 0.1967 & 0.0651 & 45 & 30 & 29 & 29 & 30 & .5074 & 0.2585 & 200 & 100 \\
\hline 11 & 11 & 12 & 0.3744 & 0.1298 & 60 & 35 & 30 & 30 & 31 & 0.9745 & 0.9629 & 150 & 70 \\
\hline 12 & 12 & 13 & 1.4680 & 1.1549 & 60 & 35 & 31 & 31 & 32 & 0.3105 & 0.3619 & 210 & 100 \\
\hline 13 & 13 & 14 & 0.5416 & 0.7129 & 120 & 80 & 32 & 32 & 33 & 0.3411 & 0.5302 & 60 & 40 \\
\hline 14 & 14 & 15 & 0.5909 & 0.5260 & 60 & 10 & - & - & - & - & - & - & - \\
\hline 15 & 15 & 16 & 0.7462 & 0.5449 & 60 & 20 & - & - & - & - & - & - & - \\
\hline 16 & 16 & 17 & 1.2889 & 1.7210 & 60 & 20 & - & - & - & - & - & - & - \\
\hline 17 & 17 & 18 & 0.7320 & 0.5739 & 90 & 40 & - & - & - & - & - & - & - \\
\hline 18 & 2 & 19 & 0.1640 & 0.1565 & 90 & 40 & - & - & - & - & - & - & - \\
\hline 19 & 19 & 20 & 1.5042 & 1.3555 & 90 & 40 & - & - & - & - & - & - & - \\
\hline
\end{tabular}

Table 2. System data of 12 buses and 11 branches system

\begin{tabular}{|c|c|c|c|c|c|c|}
\hline \multirow[b]{2}{*}{ Branch no. } & \multirow[b]{2}{*}{ Sending end } & \multirow{2}{*}{$\begin{array}{l}\text { Receiving } \\
\text { end }\end{array}$} & \multirow{2}{*}{$\begin{array}{c}\mathrm{R} \\
\text { (ohms) }\end{array}$} & \multirow{2}{*}{$\begin{array}{c}\mathrm{X} \\
\text { (ohms) }\end{array}$} & \multicolumn{2}{|c|}{ Load at node $i$} \\
\hline & & & & & $\begin{array}{l}\mathrm{PL} \\
(\mathrm{kW})\end{array}$ & $\begin{array}{c}\mathrm{QL} \\
\text { (kVAR) }\end{array}$ \\
\hline & & & & & 0 & 0 \\
\hline 1 & 1 & 2 & 1.093 & 0.455 & 6 & 60 \\
\hline 2 & 2 & 3 & 1.184 & 0.494 & $\begin{array}{l}00 \\
40\end{array}$ & $\begin{array}{l}00 \\
30\end{array}$ \\
\hline 3 & 3 & 4 & 2.095 & 0.873 & $\begin{array}{l}40 \\
55\end{array}$ & $\begin{array}{l}30 \\
55\end{array}$ \\
\hline 4 & 4 & 5 & 3.188 & 1.329 & 55 & 55 \\
\hline 5 & 5 & 6 & 1.093 & 0.455 & 30 & 30 \\
\hline 6 & 6 & 7 & 1.002 & 0.417 & 20 & $\begin{array}{l}15 \\
55\end{array}$ \\
\hline 7 & 7 & 8 & 4.403 & 1.215 & $\begin{array}{l}53 \\
15\end{array}$ & $\begin{array}{l}55 \\
45\end{array}$ \\
\hline 8 & 8 & 9 & 5.642 & 1.597 & 45 & 45 \\
\hline 9 & 9 & 10 & 2.89 & 0.818 & 40 & 40 \\
\hline 10 & 10 & 11 & 1.514 & 0.428 & $\begin{array}{l}35 \\
40\end{array}$ & 30 \\
\hline 11 & 11 & 12 & 1.238 & 0.351 & $\begin{array}{l}40 \\
15\end{array}$ & $\begin{array}{l}30 \\
15\end{array}$ \\
\hline
\end{tabular}


Table 3. System data for modified 119-bus distribution network

\begin{tabular}{|c|c|c|c|c|c|c|c|c|c|c|c|c|c|}
\hline \multirow{2}{*}{$\begin{array}{c}\text { Line } \\
\#\end{array}$} & \multirow{2}{*}{$\begin{array}{c}\text { Node } \\
i\end{array}$} & \multirow{2}{*}{$\begin{array}{c}\text { Node } \\
j\end{array}$} & \multirow{2}{*}{$\begin{array}{l}\mathrm{R} \\
(\Omega)\end{array}$} & \multirow{2}{*}{$\begin{array}{c}\mathrm{X} \\
(\Omega)\end{array}$} & \multicolumn{2}{|c|}{ Load at node $j$} & \multirow{2}{*}{$\begin{array}{c}\text { Line } \\
\#\end{array}$} & \multirow{2}{*}{$\begin{array}{c}\text { Node } \\
i\end{array}$} & \multirow{2}{*}{$\begin{array}{c}\text { Node } \\
j\end{array}$} & \multirow{2}{*}{$\begin{array}{c}\mathrm{R} \\
(\Omega)\end{array}$} & \multirow{2}{*}{$\begin{array}{l}\mathrm{X} \\
(\Omega)\end{array}$} & \multicolumn{2}{|c|}{ Load at node $i$} \\
\hline & & & & & $\begin{array}{c}\mathrm{P} \\
(\mathrm{kw})\end{array}$ & $\begin{array}{c}\mathrm{Q} \\
\text { (kvar) }\end{array}$ & & & & & & $\begin{array}{c}\mathrm{P} \\
(\mathrm{kw})\end{array}$ & $\begin{array}{c}\mathrm{Q} \\
(\mathrm{kw})\end{array}$ \\
\hline 1 & 1 & 2 & 0.036 & 0.01296 & 101.14 & 0.12 & 60 & 60 & 61 & 0.207 & 0.0747 & 90.758 & 0.69 \\
\hline 2 & 2 & 3 & 0.033 & 0.01188 & 11.292 & 0.11 & 61 & 61 & 62 & 0.247 & 0.8922 & 47.7 & 0.823 \\
\hline 3 & 2 & 4 & 0.045 & 0.0162 & 21.845 & 0.15 & 62 & 31 & 63 & 0.187 & 0.261 & 369.7 & 0.623 \\
\hline 4 & 4 & 5 & 0.015 & 0.054 & 63.602 & 0.05 & 63 & 63 & 64 & 0.133 & 0.099 & 321.64 & 0.443 \\
\hline 5 & 5 & 6 & 0.015 & 0.054 & 68.604 & 0.05 & 64 & 64 & 65 & 0.070 & 0.044 & 150.64 & 0.223 \\
\hline 6 & 6 & 7 & 0.015 & 0.0125 & 61.725 & 0.05 & 65 & 1 & 66 & 0.028 & 0.0418 & 463.74 & 0.093 \\
\hline 7 & 7 & 8 & 0.018 & 0.014 & 11.503 & 0.06 & 66 & 66 & 67 & 0.117 & 0.2016 & 52.006 & 0.39 \\
\hline 8 & 8 & 9 & 0.021 & 0.063 & 51.073 & 0.07 & 67 & 67 & 68 & 0.255 & 0.0918 & 100.34 & 0.85 \\
\hline 9 & 2 & 10 & 0.166 & 0.1344 & 106.77 & 0.553 & 68 & 68 & 69 & 0.21 & 0.0759 & 193.5 & 0.7 \\
\hline 10 & 10 & 11 & 0.112 & 0.0789 & 75.99 & 0.373 & 69 & 69 & 70 & 0.383 & 0.138 & 26.713 & 1.277 \\
\hline 11 & 11 & 12 & 0.187 & 0.313 & 18.687 & 0.623 & 70 & 70 & 71 & 0.504 & 0.3303 & 25.257 & 1.68 \\
\hline 12 & 12 & 13 & 0.142 & 0.1512 & 23.22 & 0.473 & 71 & 71 & 72 & 0.4 & 0.1461 & 38.713 & 1.353 \\
\hline 13 & 13 & 14 & 0.18 & 0.118 & 117.5 & 0.6 & 72 & 72 & 73 & 0.962 & 0.761 & 395.14 & 3.207 \\
\hline 14 & 14 & 15 & 0.15 & 0.045 & 28.79 & 0.5 & 73 & 73 & 74 & 0.165 & 0.06 & 239.74 & 0.55 \\
\hline 15 & 15 & 16 & 0.16 & 0.18 & 26.45 & 0.533 & 74 & 74 & 75 & 0.303 & 0.1092 & 84.363 & 1.01 \\
\hline 16 & 16 & 17 & 0.157 & 0.171 & 25.23 & 0.523 & 75 & 75 & 76 & 0.303 & 0.1092 & 22.482 & 1.01 \\
\hline 17 & 11 & 18 & 0.218 & 0.285 & 11.906 & 0.727 & 76 & 76 & 77 & 0.206 & 0.144 & 1614.775 & 110.687 \\
\hline 18 & 18 & 19 & 0.118 & 0.185 & 78.523 & 0.393 & 77 & 77 & 78 & 0.233 & 0.084 & 129.817 & 110.777 \\
\hline 19 & 19 & 20 & 0.16 & 0.196 & 351.4 & 0.533 & 78 & 78 & 79 & 0.591 & 0.1773 & 1122.43 & 111.97 \\
\hline 20 & 20 & 21 & 0.12 & 0.189 & 164.2 & 0.4 & 79 & 79 & 80 & 0.126 & 0.0453 & 145.37 & 110.42 \\
\hline 21 & 21 & 22 & 0.12 & 0.0789 & 54.594 & 0.4 & 80 & 67 & 81 & 0.559 & 0.3687 & 223.22 & 1.863 \\
\hline 22 & 22 & 23 & 1.41 & 0.723 & 39.65 & 4.7 & 81 & 81 & 82 & 0.186 & 0.1227 & 162.47 & 0.62 \\
\hline 23 & 23 & 24 & 0.293 & 0.1348 & 95.178 & 0.977 & 82 & 82 & 83 & 0.186 & 0.1227 & 437.92 & 0.62 \\
\hline 24 & 24 & 25 & 0.133 & 0.104 & 150.22 & 0.443 & 83 & 83 & 84 & 0.26 & 0.139 & 183.03 & 0.867 \\
\hline 25 & 25 & 26 & 0.178 & 0.134 & 24.62 & 0.593 & 84 & 84 & 85 & 0.154 & 0.148 & 183.03 & 0.513 \\
\hline 26 & 26 & 27 & 0.178 & 0.134 & 24.62 & 0.593 & 85 & 85 & 86 & 0.23 & 0.128 & 119.29 & 0.767 \\
\hline 27 & 27 & 28 & 0.1866 & 0.127 & 53.336 & 0.622 & 86 & 86 & 87 & 0.252 & 0.106 & 27.96 & 0.84 \\
\hline 28 & 4 & 29 & 0.015 & 0.0296 & 522.62 & 0.05 & 87 & 87 & 88 & 0.18 & 0.148 & 26.515 & 0.6 \\
\hline 29 & 29 & 30 & 0.012 & 0.0276 & 59.117 & 0.04 & 88 & 82 & 89 & 0.16 & 0.182 & 257.16 & 0.533 \\
\hline 30 & 30 & 31 & 0.12 & 0.2766 & 99.554 & 0.4 & 89 & 89 & 90 & 0.2 & 0.23 & 20.6 & 0.667 \\
\hline 31 & 31 & 32 & 0.21 & 0.243 & 318.5 & 0.7 & 90 & 90 & 91 & 0.16 & 0.393 & 11.806 & 0.533 \\
\hline 32 & 32 & 33 & 0.12 & 0.054 & 456.14 & 0.4 & 91 & 91 & 92 & 0.16 & 0.393 & 11.806 & 0.533 \\
\hline 33 & 33 & 34 & 0.178 & 0.234 & 136.79 & 0.593 & 92 & 68 & 93 & 0.669 & 0.2412 & 42.96 & 2.23 \\
\hline 34 & 34 & 35 & 0.178 & 0.234 & 83.302 & 0.593 & 93 & 93 & 94 & 0.266 & 0.1227 & 34.93 & 0.887 \\
\hline 35 & 35 & 36 & 0.154 & 0.162 & 93.082 & 0.513 & 94 & 94 & 95 & 0.266 & 0.1227 & 66.79 & 0.887 \\
\hline 36 & 36 & 37 & 0.21 & 0.1383 & 42.361 & 0.7 & 95 & 95 & 96 & 0.266 & 0.1227 & 81.748 & 0.887 \\
\hline 37 & 37 & 38 & 0.12 & 0.0789 & 51.653 & 0.4 & 96 & 96 & 97 & 0.266 & 0.1227 & 66.526 & 0.887 \\
\hline 38 & 38 & 39 & 0.15 & 0.0987 & 57.965 & 0.5 & 97 & 97 & 98 & 0.233 & 0.115 & 15.96 & 0.777 \\
\hline 39 & 39 & 40 & 0.15 & 0.0987 & 1205.1 & 0.5 & 98 & 98 & 99 & 0.496 & 0.138 & 60.48 & 1.653 \\
\hline 40 & 40 & 41 & 0.24 & 0.1581 & 146.66 & 0.8 & 99 & 95 & 100 & 0.196 & 0.18 & 224.85 & 0.653 \\
\hline 41 & 41 & 42 & 0.12 & 0.0789 & 56.608 & 0.4 & 100 & 100 & 101 & 0.196 & 0.18 & 367.42 & 0.653 \\
\hline 42 & 42 & 43 & 0.405 & 0.1458 & 40.184 & 1.35 & 101 & 101 & 102 & 0.1866 & 0.122 & 11.7 & 0.622 \\
\hline 43 & 43 & 44 & 0.405 & 0.1458 & 283.41 & 1.35 & 102 & 102 & 103 & 0.0746 & 0.318 & 30.392 & 0.249 \\
\hline 44 & 44 & 45 & 0.405 & 0.1458 & 283.41 & 1.35 & 103 & 103 & 104 & 0.0746 & 0.318 & 30.392 & 0.249 \\
\hline 45 & 30 & 46 & 0.33 & 0.194 & 55.134 & 1.1 & 104 & 1 & 105 & 0.0625 & 0.0265 & 47.572 & 0.208 \\
\hline 46 & 46 & 47 & 0.31 & 0.194 & 38.998 & 1.033 & 105 & 105 & 106 & 0.1501 & 0.234 & 350.3 & 0.5 \\
\hline 47 & 47 & 48 & 0.13 & 0.194 & 342.6 & 0.433 & 106 & 106 & 107 & 0.1347 & 0.0888 & 449.29 & 0.449 \\
\hline 48 & 48 & 49 & 0.28 & 0.15 & 278.56 & 0.933 & 107 & 107 & 108 & 0.2307 & 0.1203 & 168.46 & 0.769 \\
\hline 49 & 49 & 50 & 1.18 & 0.85 & 240.24 & 3.933 & 108 & 108 & 109 & 0.447 & 0.1608 & 134.25 & 1.49 \\
\hline 50 & 50 & 51 & 0.42 & 0.2436 & 66.562 & 1.4 & 109 & 109 & 110 & 0.1632 & 0.0588 & 66.024 & 0.544 \\
\hline 51 & 51 & 52 & 0.27 & 0.0972 & 39.76 & 0.9 & 110 & 110 & 111 & 0.33 & 0.099 & 83.647 & 1.1 \\
\hline 52 & 52 & 53 & 0.339 & 0.1221 & 31.964 & 1.13 & 111 & 111 & 112 & 0.156 & 0.0561 & 419.34 & 0.52 \\
\hline 53 & 53 & 54 & 0.27 & 0.1779 & 20.758 & 0.9 & 112 & 112 & 113 & 0.3819 & 0.1374 & 135.88 & 1.273 \\
\hline 54 & 30 & 55 & 0.391 & 0.141 & 26.86 & 1.303 & 113 & 113 & 114 & 0.1626 & 0.0585 & 387.21 & 0.542 \\
\hline 55 & 55 & 56 & 0.406 & 0.1461 & 88.38 & 1.353 & 114 & 114 & 115 & 0.3819 & 0.1374 & 173.46 & 1.273 \\
\hline 56 & 56 & 57 & 0.406 & 0.1461 & 55.436 & 1.353 & 115 & 115 & 116 & 0.2445 & 0.0879 & 898.55 & 0.815 \\
\hline
\end{tabular}




\begin{tabular}{|c|c|c|c|c|c|c|c|c|c|c|c|c|c|}
\hline 57 & 57 & 58 & 0.706 & 0.5461 & 332.4 & 2.353 & 116 & 116 & 117 & 0.2088 & 0.0753 & 215.37 & 0.696 \\
\hline 58 & 58 & 59 & 0.338 & 0.1218 & 16.83 & 1.127 & 117 & 117 & 118 & 0.2301 & 0.0828 & 40.97 & 0.767 \\
\hline 59 & 59 & 60 & 0.338 & 6 & 49.156 & 1.127 & 118 & 105 & 119 & 0.6102 & 0.2196 & 192.9 & 2.034 \\
\hline
\end{tabular}

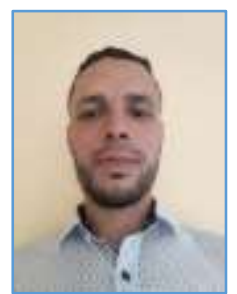

OUAIL Mohamed was born in Ain Defla in Algeria, on 16 march, 1991. He received the State Engineer degree and Master Degree in Electrical Engineering from Ecole Nationale Polytechnique (ENP), alger, Algeria in 2015-2016. He is currently an Ph.D student in university hassiba ben bouali chlef. His research interests are in the the Smart Grid and Distributed Generation, Renewable Energy, the Optimisation and stability of Distributed network.

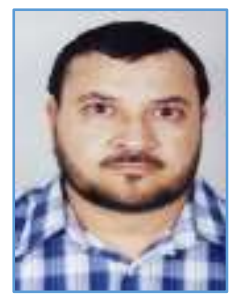

Matallah Mohamed was born in Arib, Algeria, in 1961. He received his $\mathrm{PhD}$ in Electrical Engineering in 1991 at the University of Swansea, UK. He is currently working as an Associate Professor at the University of KhemisMiliana, Algeria, and is a member of The LESI (Energies and Intelligent Systems) Laboratory. His research interests include Electrical Discharges in Gases and Electrical Power Networks, Distributed Generation and stability of Distributed network.

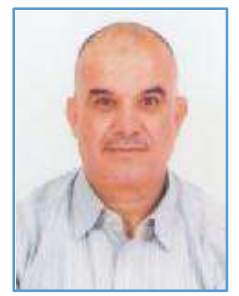

A Kansab was born in Mazouna, Algeria, in 1964.He received the doctorat degree, in Electrical Engineering from the University of Sciences and technology of Oran, Algeria, in 2008. He is currently working as an Associate Professor at the university of chlef and is a member in the LGEER Laboratory (Laboratoire Génie Electrique et Energies Renouvelables). His research interests include modeling and optimization in Electromagnetic systems and devices. 